\title{
BRAF V600E-Positive Multisite Langerhans Cell Histiocytosis in a Preterm Neonate
}

\author{
Sara V. Bates, $\mathrm{MD}^{1, *} \quad$ Ashwini Lakshmanan, MD, MPH ${ }^{2, *} \quad$ Adam L. Green, MD ${ }^{3,4}$ \\ Jefferson Terry, MD, PhD ${ }^{5}$ Gayane Badalian-Very, MD, PhD ${ }^{6}$ Barrett J. Rollins, MD, PhD 6 ,7 \\ Patricia Fleck, NNP ${ }^{8}$ Muhammad Aslam, MD ${ }^{1, \dagger}$ Barbara A. Degar, MD $3,4, \dagger$
}

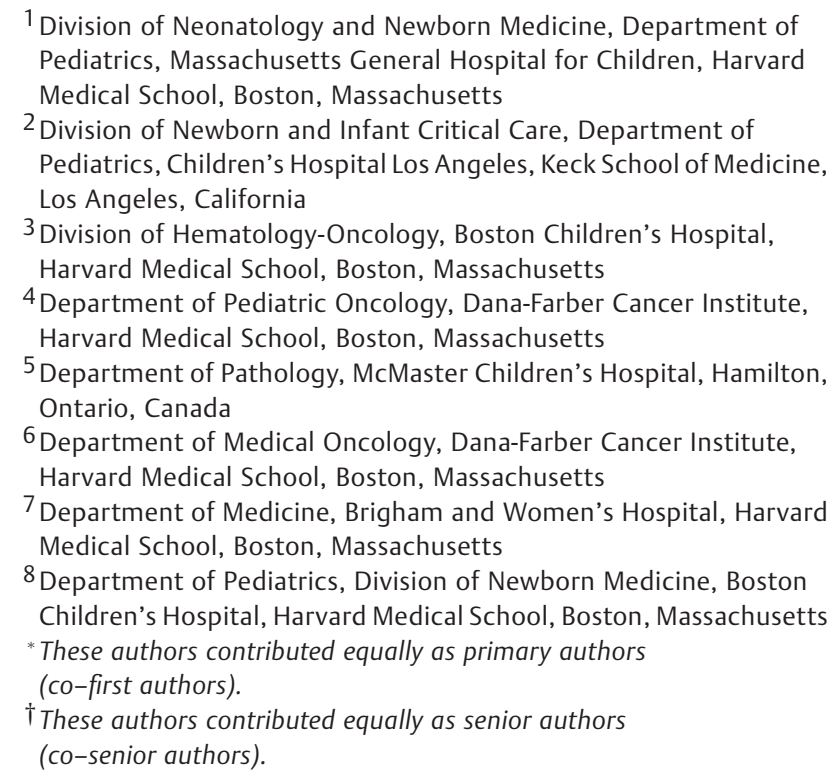

Address for correspondence Sara V. Bates, MD, Division of Newborn Medicine and Neonatology, Massachusetts General Hospital for Children, 55 Fruit Street, Founders 530, Boston, MA 02114

(e-mail: sbates@partners.org).

Am J Perinatol Rep 2013;3:63-66.

\section{Abstract Keywords \\ - Langerhans cell histiocytosis \\ - BRAF V600E \\ - preterm neonate \\ - multiorgan \\ - multisite \\ - hemorrhagic pustules}

Hemorrhagic pustules with a "blueberry muffin" appearance accompanied by respiratory failure in a neonate present a challenging differential diagnosis that includes infections and neoplasms. We present a case of multiorgan, multisite Langerhans cell histiocytosis (LCH), positive for the oncogenic BRAF V600E mutation, in a preterm neonate. Infants with LCH pose a diagnostic challenge due to their heterogeneous presentations. This case is unusual in that the newborn presented with severe multiorgan involvement. Due to the rare incidence, wide spectrum of clinical manifestations, and high mortality rate, clinicians must maintain a high index of suspicion for LCH.
"Blueberry muffin baby" is a term describing the cutaneous manifestations of various congenital infections and neoplastic diseases. Especially in infants in whom these cutaneous findings are accompanied by severe illness, providers must rapidly navigate the broad range of possibilities. Here, we outline the most likely diagnoses with this presentation and discuss a case of Langerhans cell histiocytosis (LCH) in a preterm neonate with severe multiorgan involvement. received

December 13, 2012 accepted after revision January 24, 2013 published online March 18, 2013
DOI http://dx.doi.org/ 10.1055/s-0033-1338168. ISSN 2157-6998.
Copyright (c 2013 by Thieme Medical Publishers, Inc., 333 Seventh Avenue, New York, NY 10001, USA. Tel: +1(212) 584-4662.
License terms

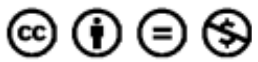




\section{Case Report}

A 4-day-old preterm male neonate was transferred to the neonatal intensive care unit (NICU) for evaluation of respiratory failure and cutaneous hemorrhagic pustular lesions. The neonate was born at $33^{2 / 7}$ weeks' gestation at 2,204 g to a 36year-old gravida 5, para 2 mother. Maternal prenatal infectious history was negative. Prenatal ultrasounds detected a single lesion below the fetus' left eye that could not be further characterized.

The neonate was born via spontaneous vaginal delivery. In the delivery room, the newborn required intubation and cardiopulmonary resuscitation due to apnea and bradycardia. He was subsequently transferred to the NICU. On exam, his weight and length were at the 75th percentile, with head circumference at the 25th percentile. Exam revealed multiple cutaneous lesions of varying size all over his body, including his oral mucosa, hands, and feet ( - Fig. 1A). The spleen tip and liver edge were both palpable 1 to $2 \mathrm{~cm}$ below the costal margin.

Initial laboratory evidence was significant for $\mathrm{pH} 6.6$ with $\mathrm{PCO}_{2} 86$ and $\mathrm{HCO}_{3} 24$, hemoglobin $17 \mathrm{~g} / \mathrm{dL}$, WBC 19,000 cells/ $\mu \mathrm{L}$, platelet count 147,000 cells/ $\mu \mathrm{L}$, Gamma-Glutamyl Transpeptidase (GGT) 1,014 U/L, total bilirubin $11 \mathrm{mg} / \mathrm{dL}$, direct bilirubin $2.5 \mathrm{mg} / \mathrm{dL}$, prothrombin time 15.2 seconds and partial thromboplastin time 56 seconds. On peripheral blood smear, mature neutrophils were predominant, and no blasts were seen. These data were interpreted as showing severe
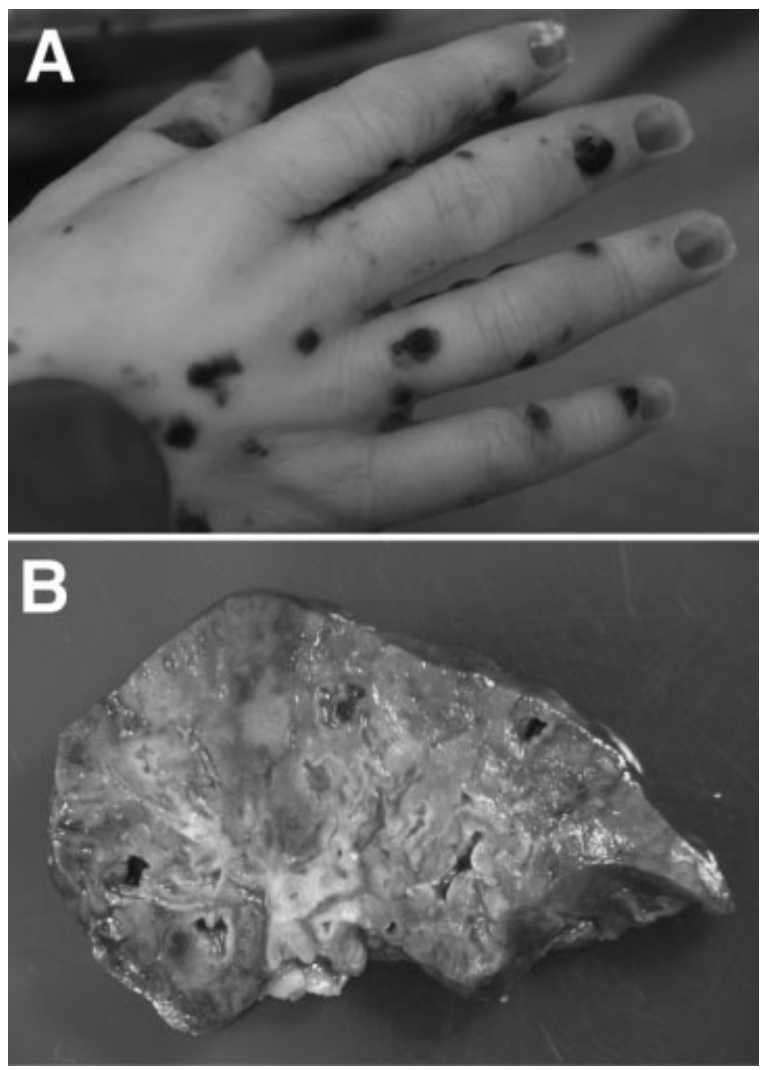

Fig. 1 (A) The skin was diffusely involved by dark, crusted pustules. (B) The lung parenchyma appeared focally consolidated with cavitations and intervening normal-appearing areas of lung parenchyma. uncompensated respiratory acidosis, mild erythroblastosis without evidence of marrow infiltration, and hepatic dysfunction leading to coagulopathy.

The newborn was transitioned from conventional mechanical ventilation to high-frequency ventilation and developed a pneumothorax. Upon transfer to a tertiary NICU, refractory hypoxia and a combined metabolic and respiratory acidosis persisted despite high-frequency ventilation and the addition of nitric oxide. A chest radiograph illustrated hyperinflation and cystic-appearing blebs. The neonate had negative tests for cytomegalovirus (CMV), herpes simplex virus (HSV), varicella zoster virus, human immunodeficiency virus, paramyxovirus, toxoplasma, syphilis, parvovirus B19, and rubella. Placental pathology was consistent with chronic and focal villitis. The initial microscopic appearance of this disease process on abdominal skin biopsy was highly atypical and suggestive of hematologic malignancy; leukemia cutis was first considered, but immunohistochemistry suggested LCH. Despite maximal respiratory and cardiovascular support, the newborn's condition deteriorated, and care was redirected toward comfort measures.

The family consented to a full autopsy. External examination demonstrated diffuse black papules and pustules preferentially involving the hands and feet. Internal examination revealed disease involvement of multiple sites in the chest and abdomen. Most striking were the lungs, which appeared consolidated and contained multiple cavitations and hemorrhagic nodules with interspersed normal-appearing parenchyma (-Fig. 1B). The thymus was enlarged and friable. Tumor nodules were found on the gastrointestinal tract, liver, pancreas, and adrenal glands. Histologic analysis of the skin lesions, lungs, thymus, and abdominal tumor nodules demonstrated a histiocytic infiltrate with occasional eosinophils and other inflammatory cells. The histiocytes had poorly defined cell borders and grooved nuclei, and they exhibited immunohistochemical expression of S100, CD1a, and Langerin, establishing the diagnosis of multisite, multisystem $\mathrm{LCH}$. DNA extracted from the lesional tissue was positive for the BRAF V600E mutation on pyrosequencing.

\section{Discussion}

The differential diagnosis of hemorrhagic vesicopustules and respiratory failure in a preterm neonate can be dichotomized into infectious and noninfectious etiologies. Congenital infections should always be considered, including those listed in - Table 1. CMV and HSV can present with cutaneous manifestations and systemic illness as presented here, such as profound respiratory and multiorgan involvement. ${ }^{1}$ However, diagnoses like toxoplasmosis or syphilis are unlikely given the lack of lymphadenopathy. ${ }^{2}$

In severely ill infants, congenital malignancies should be the noninfectious diagnoses highest on the differential. Congenital leukemias, most often acute myelogenous leukemia and occasionally acute lymphocytic leukemia, are the neonatal cancers most associated with cutaneous manifestations but are unlikely to directly cause lung disease. ${ }^{3}$ Neuroblastoma and rhabdomyosarcoma can present in 
Table 1 Differential diagnosis of hemorrhagic vesicopustules and respiratory failure in a preterm infant

\begin{tabular}{|l|l|}
\hline Infectious & Noninfectious \\
\hline Bullous impetigo & Congenital leukemia \\
\hline Cytomegalovirus & Generalized eruptive histiocytoma \\
\hline Congenital candidiasis & Hemolytic disease of the newborn \\
\hline Herpes simplex virus & Hereditary spherocytosis \\
\hline Listeriosis & Incontinentia pigmenti \\
\hline Parvovirus B19 & Indeterminate cell histiocytoma \\
\hline Rubella & Juvenile xanthogranulomas \\
\hline Syphilis & Langerhans cell histiocytosis \\
\hline Toxoplasmosis & Neonatal hemangiomatosis \\
\hline Varicella & Neuroblastoma \\
\hline & Rhabdoid tumor \\
\hline & Rhabdomyosarcoma \\
\hline
\end{tabular}

neonates with skin metastases and produce lung tumors, although these would be unlikely to be cystic.

LCH is a rare, proliferative disease of Langerhans cells, usually affecting children, with an incidence of five per million. ${ }^{4}$ What was formerly considered a group of distinct histiocytic disorders, including Hand-Schüller-Christian disease, LettererSiwe disease, eosinophilic granuloma, and histiocytosis $\mathrm{X}$, is now unified into a single disease. ${ }^{5}$ This classification emerged with the discovery that the abnormal cells in all of these disorders have ultrastructural features and surface antigens characteristic of Langerhans cells. ${ }^{6-9}$ Today, LCH is classified based on number of sites and organs involved. Single-site disease is the most predominant and has a favorable prognosis. Multisystem disease without risk organ involvement has a good prognosis, whereas multisystem disease involving any risk organ (lung, liver, or bone marrow) is often fatal. ${ }^{10,11}$

Infants with $\mathrm{LCH}$ pose a diagnostic challenge due to their heterogeneous presentations. There have been small case series attempting to correlate clinical findings with prognosis, but results are inconsistent and data are scant. One retrospective series found that the most common presenting skin lesions were erythematous, often crusted, and vesiculopustular in nature and, more importantly, that the type of lesion could not predict the extent of other organ system involvement. $^{12}$

Due to the rare incidence, varied presentation, and significant potential for mortality, clinicians must maintain a high index of suspicion for this diagnosis in infants. Because skin disease is a common presenting feature and the site most amenable to biopsy, skin biopsy with immunohistochemistry is crucial. The histologic appearance of LCH is characteristic, and CD1a staining is specific for Langerhans cells. ${ }^{13}$ Importantly, a majority of infants with cutaneous LCH also have or go on to develop multisystem disease, ${ }^{14}$ which must be diagnosed promptly so that treatment can be initiated. Laboratory tests upon diagnosis should include complete blood count, liver function tests, and cultures if infectious symptoms are present. Bone marrow aspiration and biopsy may be useful in the evaluation of cytopenias. ${ }^{15}$ Imaging should include a chest radiograph, and chest computed tomography should be obtained if pulmonary symptoms are present. A skeletal survey and abdominal ultrasound should also be considered to evaluate for bone involvement and hepatosplenomegaly, respectively. Our patient's workup was limited due to his physiologic instability.

It is now known that the Langerhans cells in LCH lesions are biologically distinct from normal Langerhans cells found in skin. ${ }^{15}$ Whether $\mathrm{LCH}$ is neoplastic or reactive in nature has been an area of great debate. ${ }^{16,17}$ A recent study found somatic mutations in the oncogene BRAF V600E in 57\% of archived cases of $\mathrm{LCH}$, lending support to a neoplastic basis. ${ }^{18}$ The V600E mutation leads to constitutive activation of the BRAF kinase, causing cell proliferation and survival. This mutation is found in a variety of human tumors, most commonly cutaneous melanoma, although it is also found in a majority of benign melanocytic nevi, suggesting that further genetic changes are necessary for malignant transformation, at least in melanoma. ${ }^{19}$

Although conventional multiagent chemotherapy is effective in about $70 \%$ of children with high-risk, multisystem $\mathrm{LCH}^{20}$ our patient was not a candidate for this type of treatment at the time of diagnosis due to the presence of multiorgan system failure. Targeted therapy with BRAF inhibitors may soon offer a less toxic alternative, however. These agents have led to prolonged survival in melanoma in phase III trials, ${ }^{21,22}$ and a recent case series reported sustained responses to vemurafenib in adults with $\mathrm{LCH}^{23}$

This report is one of only a few in the literature of multisystemic LCH in a preterm newborn leading to multiorgan system failure and death. It represents the first published case of $\mathrm{LCH}$ presenting perinatally to be associated with the BRAF V600E mutation.

\section{References}

1 Syridou G, Spanakis N, Konstantinidou A, et al. Detection of cytomegalovirus, parvovirus B19 and herpes simplex viruses in cases of intrauterine fetal death: association with pathological findings. J Med Virol 2008;80:1776-1782

2 Abdalla KF, el Fakahany AF, Arafa MA, Salama MM, Morsy TA. Congenital toxoplasmosis among premature infants with different clinical pictures in Saudi Arabia. J Egypt Soc Parasitol 1994;24: 643-648

3 Isaacs H Jr. Cutaneous metastases in neonates: a review. Pediatr Dermatol 2011;28:85-93

4 Bechan GI, Egeler RM, Arceci RJ. Biology of Langerhans cells and Langerhans cell histiocytosis. Int Rev Cytol 2006;254:1-43

5 Nezelof C, Basset F, Rousseau MF. Histiocytosis X histogenetic arguments for a Langerhans cell origin. Biomedicine 1973;18: 365-371

6 Basset F, Turiaf MJ. [Identification by electron microscope of particles of probable viral nature in the granulomatous connections of a pulmonary histiocytosis "X"]. C R Acad Sci Hebd Seances Acad Sci D 1965;261:3701-3

7 Cancilla PA, Lahey ME, Carnes WH. Cutaneous lesions of LettererSiwe disease. Electron microscopic study. Cancer 1967;20:1986-91

8 Rousseau-Merck MF, Barbey S, Jaubert F, Bach MA, Chatenoud L, Nezelof C. Reactivity of histiocytosis X cells with monoclonal antibodies. Pathol Res Pract 1983;177:8-12 


\section{Multisite Langerhans Cell Histiocytosis in a Preterm Neonate Bates et al.}

9 Geissmann F, Lepelletier Y, Fraitag S, et al. Differentiation of Langerhans cells in Langerhans cell histiocytosis. Blood 2001;97: 1241-1248

10 Nezelof C, Frileux-Herbet F, Cronier-Sachot J. Disseminated histiocytosis X: analysis of prognostic factors based on a retrospective study of 50 cases. Cancer 1979;44:1824-1838

11 Guyot-Goubin A, Donadieu J, Barkaoui M, Bellec S, Thomas C, Clavel J. Descriptive epidemiology of childhood Langerhans cell histiocytosis in France, 2000-2004. Pediatr Blood Cancer 2008;51:71-75

12 Stein SL, Paller AS, Haut PR, Mancini AJ. Langerhans cell histiocytosis presenting in the neonatal period: a retrospective case series. Arch Pediatr Adolesc Med 2001;155:778-783

13 Newman B, Hu W, Nigro K, Gilliam AC. Aggressive histiocytic disorders that can involve the skin. J Am Acad Dermatol 2007;56: 302-316

14 Minkov M, Prosch H, Steiner M, et al. Langerhans cell histiocytosis in neonates. Pediatr Blood Cancer 2005;45:802-807

15 Allen CE, Li L, Peters TL, et al. Cell-specific gene expression in Langerhans cell histiocytosis lesions reveals a distinct profile compared with epidermal Langerhans cells. J Immunol 2010; 184:4557-4567

16 Degar BA, Rollins BJ. Langerhans cell histiocytosis: malignancy or inflammatory disorder doing a great job of imitating one? Dis Model Mech 2009;2:436-439
17 Querings K, Starz H, Balda BR. Clinical spectrum of cutaneous Langerhans' cell histiocytosis mimicking various diseases. Acta Derm Venereol 2006;86:39-43

18 Badalian-Very G, Vergilio JA, Degar BA, et al. Recurrent BRAF mutations in Langerhans cell histiocytosis. Blood 2010;116: 1919-1923

19 Michaloglou C, Vredeveld LC, Mooi WJ, Peeper DS. BRAF(E600) in benign and malignant human tumours. Oncogene 2008;27: 877-895

20 Gadner H, Grois N, Pötschger U, et al; Histiocyte Society. Improved outcome in multisystem Langerhans cell histiocytosis is associated with therapy intensification. Blood 2008;111:2556-2562

21 Chapman PB, Hauschild A, Robert C, et al; BRIM-3 Study Group. Improved survival with vemurafenib in melanoma with BRAF V600E mutation. N Engl J Med 2011;364:2507-2516

22 Hauschild A, Grob JJ, Demidov LV, et al. Dabrafenib in BRAFmutated metastatic melanoma: a multicentre, open-label, phase 3 randomised controlled trial. Lancet 2012;380:358-365

23 Haroche J, Cohen-Aubart F, Emile JF, Arnaud L, Maksud P, Charlotte F, Cluzel P, Drier A, Hervier B, Benameur N, Besnard S, Donadieu J, Amoura Z. Dramatic efficacy of vemurafenib in both multisystemic and refractory Erdheim-Chester disease and Langerhans cell histiocytosis harboring the BRAF V600E mutation. Blood, February 28, 2013;121(9); 1495-500 